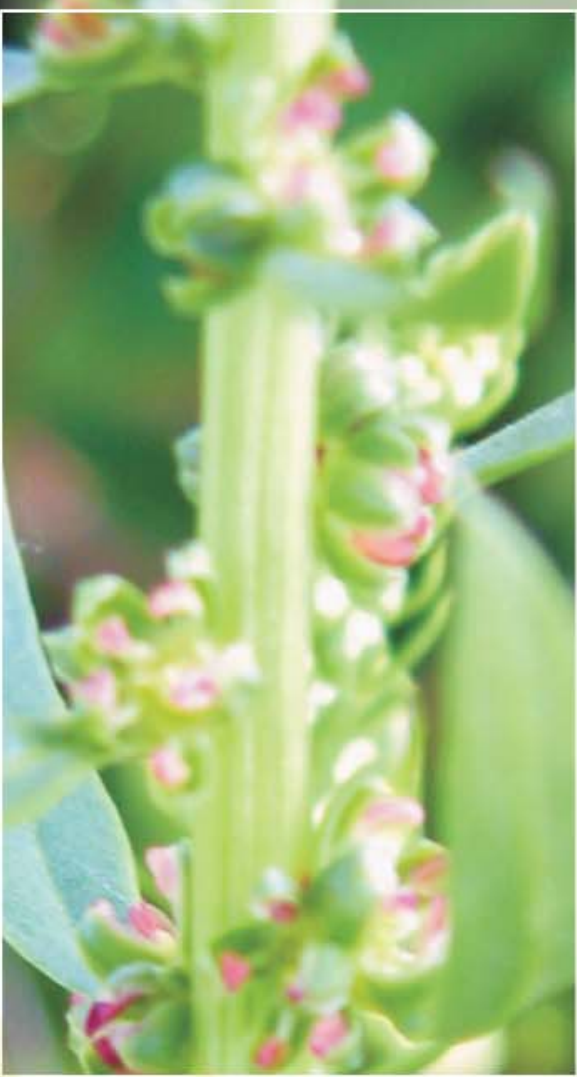

\title{
ОСОБЕННОСТИ ФЕНОТИПИЧЕСКОГО ПРОЯВЛЕНИЯ
} ПРИЗНАКА ЦМС СЕМЕННЫХ РАСТЕНИЙ СВЕКЛЫ СТОЛОВОЙ

Федорова М.И. - д. с.-х. наук, профессор, главный н.с. лаб. селекции и семеноводства столовых корнеплодов

ветрова С.А. - М.н.с. лаб. селекции и семеноводства столовых корнеплодов козарь Е.Г. - канд. С.-Х. наук, ведуший н.с. лаб. гаметных методов селекции

ГнУ Всероссийский нИИ селекции и семеноводства овошных культур

россельхозакадемии

россия, 143080, Московская область, $n$. ВНИИССОК

Тел.: +7(495)599-24-42

E-mail:vniissok@mail.ru

Изучено феномииическое ироявление признака цМС на семенных растениях свеклы смоловой, степень стерильности коморых варыировала в пределах 5-100\%. Выделено чемыре групиы иыльников по степени окрачивания, различных по диаметру, а макке числу и диамемру иыльцевых зерен. При увеличении смеиени стерильности растений диамемр и жизнеспособность пыльчевых зерен фертильных ивемков уменьиаются, снижаемся скорость роста пыльчевых мрубок.

Ключевые слова: свекла столовая, семенные растения, пыльиа, фертильность, ЦМС зучение признака мужской стерильности свекпе. Изучение особенностей проявления данного признака на уровне генеративных органов, растений, инбредных потомств свеклы столовой позволит использовать ЦМС в практической работе по созданию гетерозисных гибридов.

По мнению многих авторов у ЦМС-растений свеклы сахарной нарушены поздние этапы формирования пыльцы. В фертильных пыльниках после распада тетрад секреторный тапетум постепенно перерождается в плазмодиальный и равномерно выстилает стенки пыльников, питает микроспоры. Микроспора увеличивается, накапливает большое количество питательных веществ (сахаров, ферментов, витаминов, каротиноидов), после чего тапетум постепенно лизирует, вокруг микроспоры начинают возникать собственные оболочки, и она превращается в пыльцевое зерно. Фертильные пыльники и пыльцевые зерна окрашиваются в желтый цвет за счет каротиноидов, переходящих из тапетума. В стерильных пыльниках, начиная с распада тетрад, происходит постепенное разрушение клеток секреторного тапетума и неравномерное образование периплазмодия, в результате чего нарушаются цитоплазматические связи меж- 
ду клетками тапетума и микроспорами. Достигнув диаметра 10-13 мкм, микроспора прекращает свое дальнейшее развитие, происходит постепенное отслаивание цитоплазмы от стенок и лизирование. От микроспор остаются слипшиеся пустые оболочки. Пыльники стерильных растений свеклы сахарной белые, слегка зеленоватые (Атабекова А.И., Устинова Е.И., 1971; Артшвагер Е., 1964; Зайковская Н.Э., 1961, 1966).

На растениях свеклы столовой маркерным признаком стерильности является красная окраска пыльников (полностью или частично окрашенные). Подобное описание приводится Hara Stein и W.H. Cabelman на растениях свеклы столовой сортотипа Детройт (1959).

\section{Материалы и методы}

Исследования проводили в условиях защищенного грунта на семенных растениях первого и второго инбредных потомств. Инбредные потомства получены на основе сортопопуляции Нежность и гибридных популяций Red Ace $F_{1}$ и Red Klaud $F_{1}$. Индивидуальные растения, выделенные для получения инбредных потомств, выращивали под индивидуальными изоляторами Оценку растений по признаку ЦМС проводили в фазу массового цветения. Степень стерильности определяли как процент стерильных цветков от общего числа цветков на растении.

Определение жизнеспособности пыльцы свеклы столовой проводили по методике 3.П. Паушевой (1988) и И.Н. Голубинского (1974) на питательной среде следующего состава: ПЭГ - 6000 25\%, нитрат кальция - 15 мг/100 мл, борная кислота 5 мг/100 мл. Первый учет числа проросших пыльцевых зерен проводили через три часа. Окончательный учет и фиксацию препарата через 24 часа. Для фиксации препарата использовали дифференциальный краситель (по Данвелл Д.М.).

Микрофотосъемку производили с использованием камеры для микроскопа DCM 300 (USB 2,0). Подсчет пыльцевых зерен и измерение их параметров осуществляли с помощью программы «Scope Photo».

\section{Результаты и обсуждение}

Признак ЦМС в пределах индивидуального растения проявлялся по-разному:

- различное соотношение стерильных и фертильных пыльников $(4: 1 ; 3: 2 ; 2: 3)$ внутри цветка (рис. 1a);

- отдельные, полностью стерильные цветки в соцве-
Рис. 1. Проявление признака мужской стерильности на семенных растениях свеклы столовой.

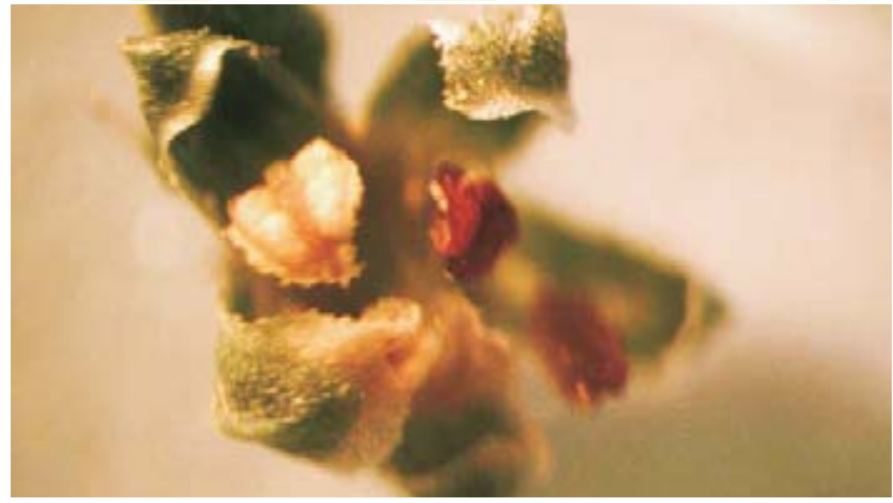

а. Отдельные стерильные пыльники в цветке

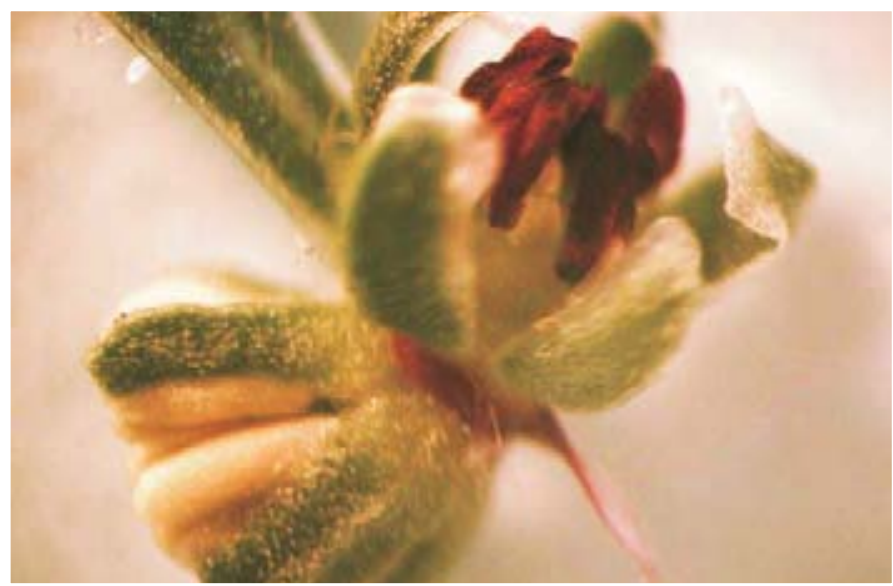

б. Отдельные стерильные цветки в соцветиях

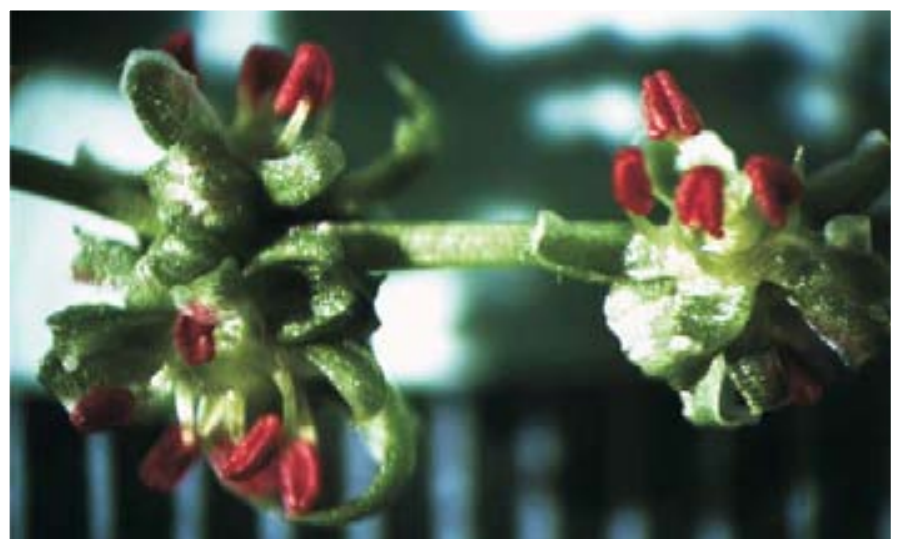

в. Отдельные стерильные ветви

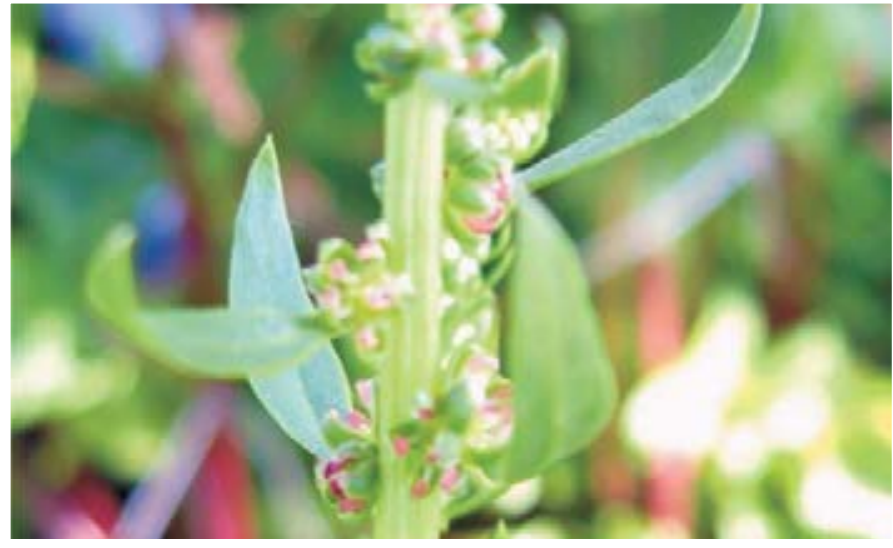

г. Полностью стерильное растение 


\section{ТЕОРИЯ И ПРАКТИКА СЕЛЕКЦИИ ОВОЩИЫХ КУЛЬТУР}

тиях (в соцветии от 1 до 3 шт.) (рис.1б);

- ветви, несущие только стерильные цветки (преимущественно центральные ветви первого порядка) (рис. 1в);

- полностью стерильное растение (рис. 1г).

Для оценки селекционного материала на ЦМС учитывали степень стерильности индивидуальных растений, которая варьировала от 5 до 100\%. У растений со степенью стерильности до 20\% отдельные стерильные цветки располагались в верхней части соцветий, чаще всего на ветвях второго порядка; со степенью стерильности 30-70\%, наблюдали наличие как полностью стерильных ветвей, так и отдельных стерильных цветков на фертильных ветвях. Растения со степенью сте- рильности 80-90\% характеризовались наличием в стерильных соцветиях отдельных фертильных цветков на ветвях любых порядков.

Подобное явление отмечено Малецким С.И. (1995) на семенных растениях свеклы сахарной. Автор объясняет это наличием двух типов митохондриальной ДНК, соответствующей известным N- и S- типам цитоплазмы. В процессе клеточных делений происходит перераспределение митохондрий и возникает разнокачественность тканей.

При сравнительной оценке характера проявления признака стерильности в инбредных потомствах, полученных из сортовых и гибридных популяций, отмечены следующие особенности. Семенные растения, полу-

\section{1. Проявление мужской стерильности и характеристика пыльцевых зерен семенных растений инбредных потомств}

\begin{tabular}{|c|c|c|c|c|c|c|c|c|c|c|}
\hline \multirow{2}{*}{$\begin{array}{l}\text { Инбредное } \\
\text { потомство }\end{array}$} & \multirow{2}{*}{$\begin{array}{c}\text { Степень } \\
\text { стериль- } \\
\text { ности, } \\
\%\end{array}$} & \multicolumn{4}{|c|}{$\begin{array}{l}\text { Окраска } \\
\text { стерильных } \\
\text { пыльников }\end{array}$} & \multicolumn{2}{|c|}{$\begin{array}{c}\text { Диаметр } \\
\text { фертильных } \\
\text { пыльцевых } \\
\text { зерен }\end{array}$} & \multirow{2}{*}{$\begin{array}{c}\text { Жизне- } \\
\text { способ- } \\
\text { ность } \\
\text { пыльцы, } \\
\%\end{array}$} & \multirow{2}{*}{$\begin{array}{l}\text { Длина } \\
\text { пыльцевой } \\
\text { трубки, } \\
\text { отн. ед. }\end{array}$} & \multirow{2}{*}{$\begin{array}{c}\text { Стериль } \\
\text { ных } \\
\text { пыльце- } \\
\text { вых } \\
\text { зерен, } \\
\%\end{array}$} \\
\hline & & $\begin{array}{c}\text { прозрач- } \\
\text { ные }\end{array}$ & $\begin{array}{l}\text { равно- } \\
\text { мерно }\end{array}$ & $\begin{array}{c}\text { не } \\
\text { равно- } \\
\text { мерно }\end{array}$ & $\begin{array}{l}\text { только } \\
\text { связник }\end{array}$ & $\begin{array}{l}\text { отн. } \\
\text { ед. }\end{array}$ & $\mathbf{v}, \%$ & & & \\
\hline $300 / 1-4-5$ & 100 & + & + & - & - & 0 & 0 & 0 & 0 & 100 \\
\hline $300 / 1-3-1$ & 80 & - & + & + & + & 49 & 12 & 0 & 0 & 85 \\
\hline $300 / 1-3-3$ & 60 & - & + & + & + & 53 & 10 & 5 & 538 & 47 \\
\hline $305 / 3$ & 30 & - & + & + & - & 56 & 11 & 37 & 605 & 8 \\
\hline $274 / 1-2-15$ & 100 & - & + & - & - & 0 & 0 & 0 & 0 & 100 \\
\hline $274 / 1-7-3$ & 50 & - & + & - & - & 53 & 9 & 3 & 314 & 8 \\
\hline $274 / 1-7-1$ & 40 & - & + & - & - & 61 & 12 & 20 & 475 & 27 \\
\hline $274 / 2-2-10$ & 15 & - & + & - & - & 56 & 11 & 28 & 462 & 6 \\
\hline $274 / 5-6-12$ & 10 & - & + & - & - & 60 & 11 & 32 & 472 & 26 \\
\hline
\end{tabular}


Рис.2. Группы пыльников по степени их окрашивания
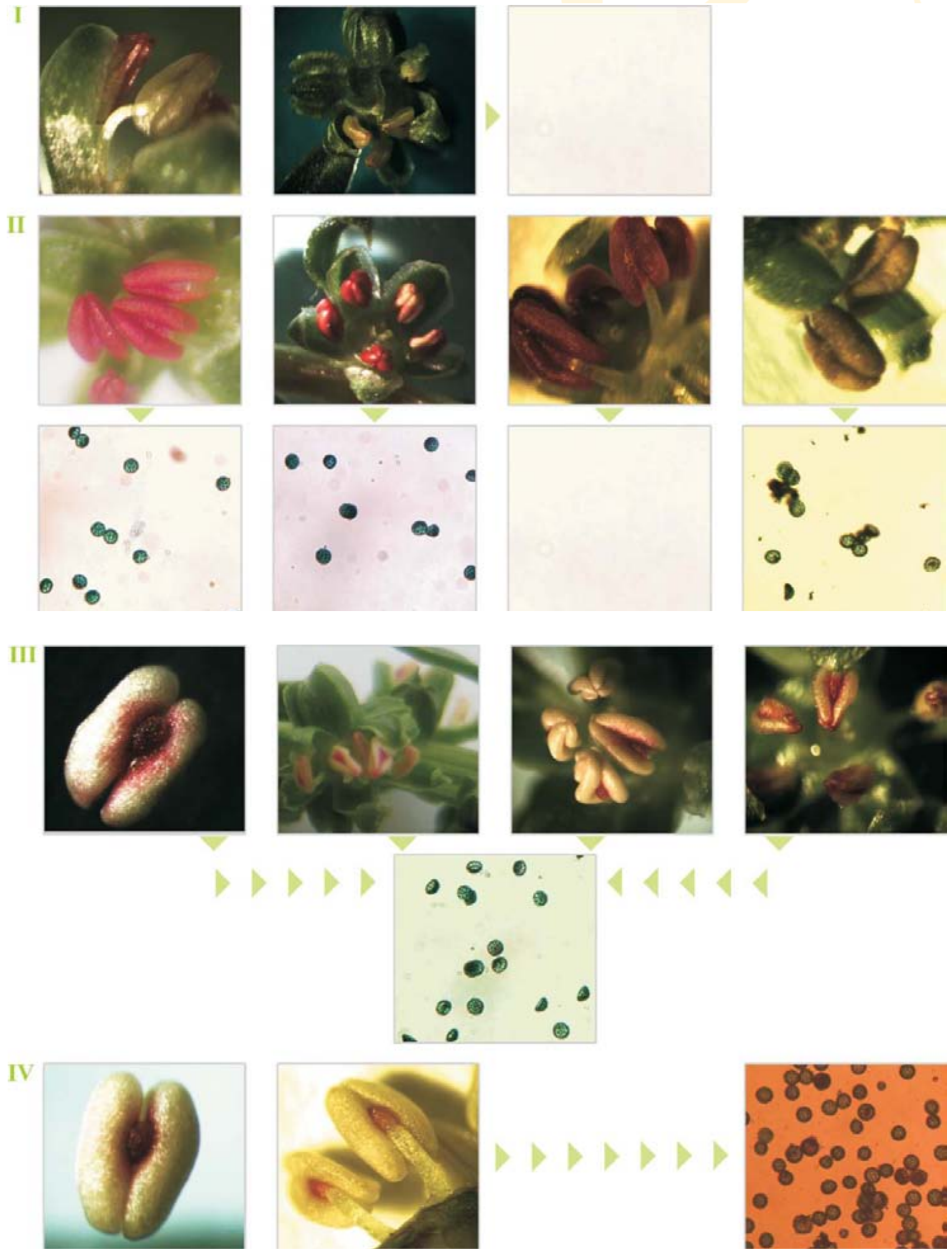


\section{ТЕОРИЯ И ПРАКТИКА СЕЛЕКЦИИ ОВОЩНЫХ КУЛЬТУР}

ченные на основе сортопопуляции Нежность, независимо от степени стерильности, имели равномерно окрашенные пыльники (красные, коричневые). У инбредных потомств с разной степенью стерильности, полученных из гибридных популяций, этот признак варьировал. Полностью стерильные семенные растения отличались наличием цветков с прозрачными или полностью окрашенными стерильными пыльниками (преимущественно красными или розовыми); пыльники в цветках растений со степенью стерильности 60-80\% характеризовались равномерной и неравномерной окраской (розовые, красные, темно-бордовые), а также наблюдали пыльники, окрашенные только в зоне связника. Растения со степенью стерильности 30\% характеризовались наличием в цветках равномерно и неравномерно окрашенных пыльников (розовых, красных).

Степень стерильности также влияет и на функциональные параметры пыльцевых зерен полностью фертильных цветков. В потомствах, полученных на основе гибридных популяций, отмечался рост числа стерильной пыльцы в фертильных цветках по мере увеличения степени стерильности растения; в потомствах, полученных из сортовой популяции, подобной закономерности не наблюдалось. С увеличением степени стерильности растения уменьшается диаметр, снижается жизнеспособность пыльцевых зерен фертильных цветков и скорость роста

Рис. 3. Содержание пыльцевых зерен в пыльниках различных фенотипических групп

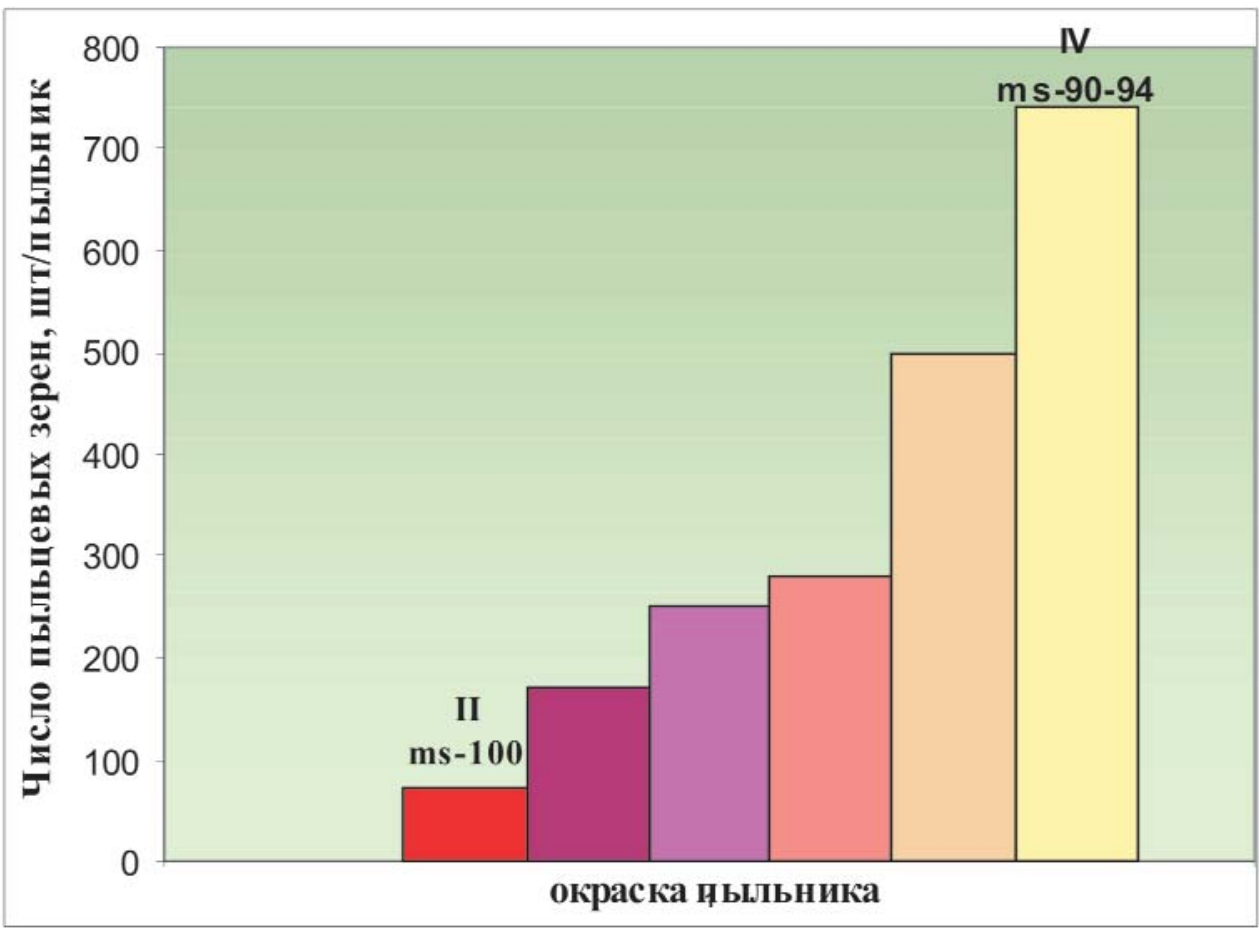

пыльцевой трубки. В потомствах, полученных на основе гибридных популяций, при увеличении степени стерильности с 30 до 60\% диаметр фертильных пыльцевых зерен снизился на 5\%; жизнеспособность пыльцы - на 32\%; а длина пыльцевой трубки - на 11\%. У растения с 80\% степенью стерильности количество фертильной пыльцы составляло 15\%, которая не прорастала. В потомствах, полученных из сортовой популяции, увеличение степени стерильности с 15 до 50\% также приводило к снижению аналогичных параметров: диаметра пыльцевых зерен на 5\%, жизнеспособности пыльцы на 25\%, длины пыльцевой трубки на 32\% (табл. 1).

При изучении проявления признака ЦМС у свеклы столовой наблюдался широкий спектр окраски пыльников стерильных растений с различной фертильностью пыльцы. По характеру окрашивания различных частей пыльника и стерильности пыльцы выделены четыре фенотипические группы:

І. Прозрачные, слегка-зеленоватые пыльники, пыльца отсутствует (по типу сахарной свеклы) (рис. 2. I).

II. Пыльники, розовые, красные, темно-бордовые, коричневые, окрашены равномерно. В темно-бордовых пыльниках пыльцевых зерен не обнаружено. Красные и розовые пыльники содержат небольшое количество полностью стерильной пыльцы. В пыльниках коричневой окраски пыльцевые зерна деформированы, слипшиеся по 2-6 штук (рис 2. II).

III. Пыльники розовые, красные, темно-бордовые, окрашены неравномерно: наиболее ярко окрашена центральная часть пыльника (связник), половинки окрашены частично, либо менее интенсивно, пыльца многочисленна и стерильна (рис. 2. III).

IV. Окрашен только связник пыльника, пыльники содержат большое количество пыльцевых зерен, доля стерильных составляет 90-94\% от общего числа (рис. 2. IV).

Установлено, что между окраской пыльников, наличием в них пыльцевых зерен и стерильностью пыльцы, как видно на рисунке 3, наблюдается оп- 
ределенная взаимосвязь. По мере снижения интенсивности окраски пыльника число пыльцевых зерен возрастает, а стерильность пыльцы снижается.

Установлена также взаимосвязь между окраской и диаметром пыльников и пыльцевых зерен, при этом взаимосвязь более выражена между окраской и диаметром пыльника. По мере снижения интенсивности окраски пыльников диаметр увеличивается от 0,4 мм до 0,95 мм (рис.4A).

Пыльцевые зерна пыльников III и IV групп по диаметру не отличались. Пыльцевые зерна II группы окраски пыльников характеризовались меньшим диаметром (рис. 4Б)

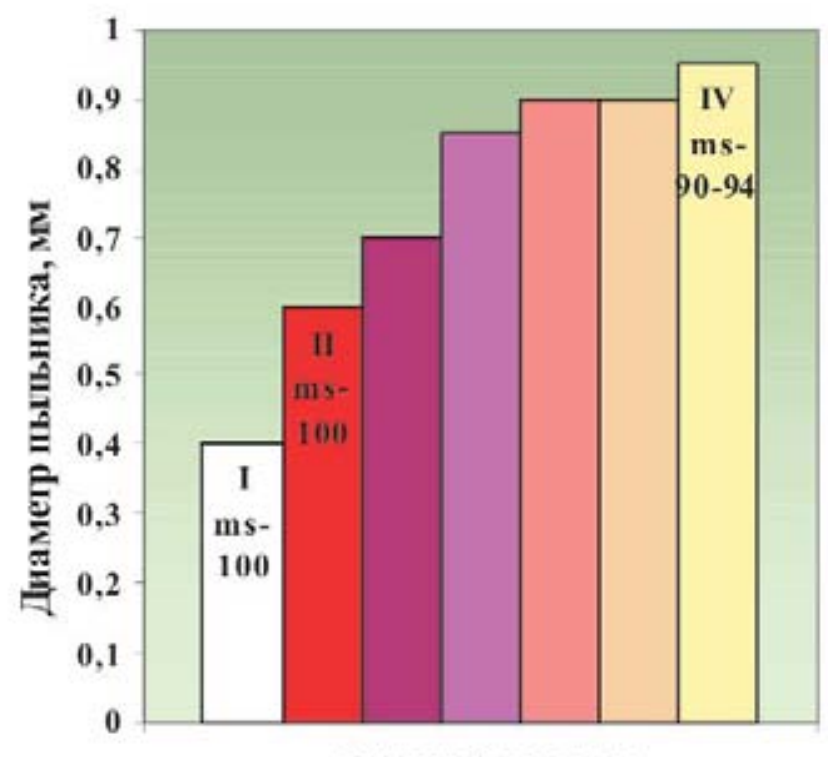

окраска Ыыьника

\section{лимераmура}

1. Артшвагер Е. Дегенерация пыльцы у сахарной свеклы с мужской стерильностью в связи с развитием тапетального плазмодия // Стерильность сахарной свеклы: Сб. переводов. - М., 1964. - С.91-97.

2. Атабекова А.И. Цитология растений / А.И. Атабекова, Е.И. Устинова. - М.: Колос, 1971. - С. 136-151.

3. Голубинский И.Н. Биология прорастания пыльцы. Киев: Наукова думка, 1974. - 368 с.

4. Зайковская Н.Э. Изучения микроспорогенеза и развитие семян у сахарной свеклы с ЦМС // Селекция рас-

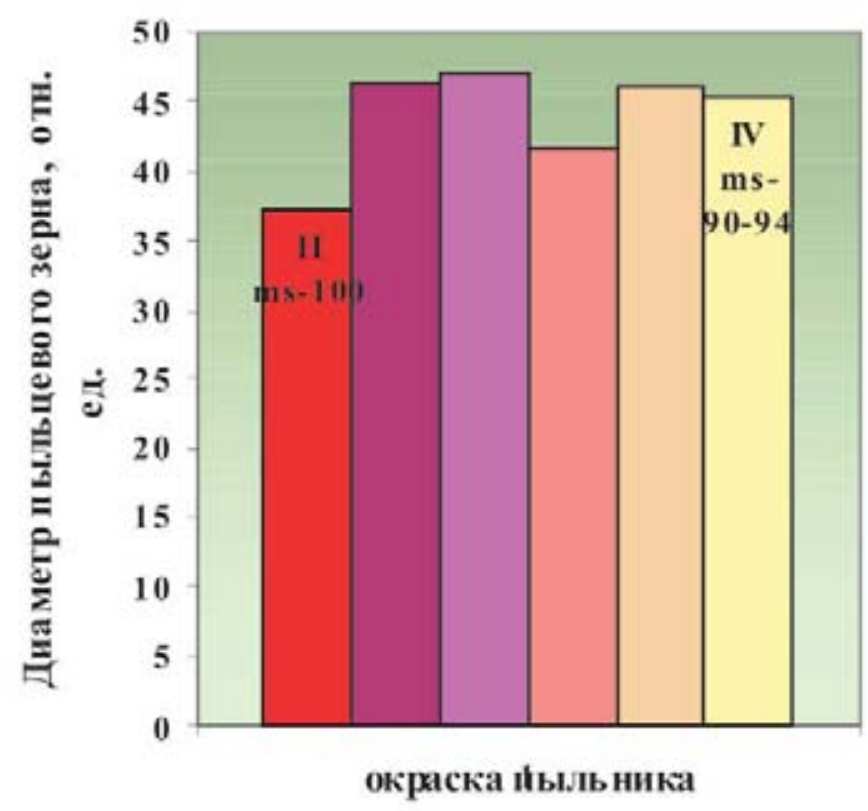

\section{Заключение}

Исходя из общеизвестного толкования генетического контроля ЦМС свеклы сахарной, предполагаем, что такое фенотипическое проявление ЦМС и взаимосвязей функциональных параметров, обусловлены перестройкой генотипа и влиянием депрессии в расщепляющихся инбредных потомствах. Таким образом, msрастения (генотипы), несущие 100\% пыльников первой - третьей групп окраски, являются основой для последующих отборов перспективного линейного материала и их можно считать исходными формами в качестве материнских компонентов при создании гетерозисных гибридов свеклы столовой.

тений с использованием ЦМС. - Киев: Урожай, 1966. с.354-368.

5. Малецкий С.И. Варьирование цитоплазматически контролируемой стерильности пыльцы у сахарной свеклы (Bets vulgaris L.) и ее связь с гетероплазмией митохондрий в клетках // Генетика. - 1995. - Т. 31 , №11. - С. 1461-1467.

6. Паушева 3.П. Практикум по цитологии растений. М.: Агропромиздат, 1988. - 271 с.

7. Stein H., Cabelman W.H. Pollen sterility in Beta vulgaris associated with red pigmentation of the Anthers.// J. of the A.S.S.B.T. -V.X. -№7.-1959.-P.612-618. 